\title{
Efektifitas Ceramah Booklet dan Buzz Group dalam Upaya Pencegahan Pneumonia pada Anak
}

\author{
Sudarwati Nababan ${ }^{*}$, Farid Agushybana ${ }^{*}$, Antono Suryoputro ${ }^{*}$ \\ *) Magister Promosi Kesehatan Fakultas Kesehatan Masyarakat Universitas Diponegoro \\ Korespondensi: fransiskusarimon@gmail.com
}

\begin{abstract}
Background: In 2016 Kopeta Health Center was ranked the 4th highest number of cough disease not pneumonia and pneumonia cases from 23 Puskesmas in Sikka District. Health education on pneumonia in this health center has often been conducted, but it seems that the results have not been effective in improving the knowledge of mothers. This is due to the fact that it is only prioritized for mothers who come as their children's illness and information provision has not been improving the knowledge of mothers on child pneumonia prevention. This study aims to compare the effectiveness of booklets provision and buzz group methods to increase knowledge, attitudes and practices of mothers in the prevention of pneumonia in children.
\end{abstract}

Method: This study employed a quasi experimental design with non-equivalent control group. The sample of this study is the mothers who have children 0-5 years old, in Nangalimang and Kabor villages and 90 mothers were selected by using systematic random sampling technique. Data was collected using face to face interview by trained enumerators guiding with closeended questionnaire that has been validated. Data were then analyzed by Chi-Square test and Manova Post Hoc Tukey.

Results: Pneumonia lectures followed by giving booklets and buzz group discussion were effective in increasing maternal knowledge and attitudes in the prevention of children pneumonia. Whereas, buzz group were more effective in improving the practice of mothers in the prevention of pneumonia than the provision of booklets. This is because the buzz method makes mothers more actively participate and creative in solving pneumonia problems by looking at other mothers' experiences. It is recommended that using buzz group lectures as an alternative method in efforts to health education for mothers, especially in the prevention of children pneumonia.

Keywords: Lectures, booklets, buzz groups, pneumonia, toddlers

\begin{abstract}
ABSTRAK
Latar Belakang: Tahun 2016 Wilayah kerja puskesmas Kopeta menempati peringkat ke-4 tertinggi kasus penyakit batuk bukan pneumonia dan pneumonia dari 23 Puskesmas di Kabupaten Sikka. Peyuluhan metode ceramah tentang pneumonia di wilayah kerja Puskesmas Kopeta telah sering dilakukan tetapi dirasa belum efektif mencapai sasaran. Hal ini disebabkan selain diutamakan bagi orang tua yang datang memeriksakan anaknya ke poli Manajemen Terpadu Balita Sakit saja, juga pengetahuan ibu yang disuluh tentang pneumonia masih tetap rendah. Penelitian ini bertujuan membandingkan efektivitas ceramah diikuti pemberian booklet dengan ceramah diikuti dengan diskusi metoda buzz group, untuk meningkatkan pengetahuan, sikap dan praktik ibu dalam pencegahan pneumonia balita.

Metode: Penelitian ini mengunakan metode quasi experimental design dengan rancangan non-equivalent control group. Sampel penelitian ini adalah ibu yang memiliki anak 0-5 tahun, di kelurahan Nangalimang dan Kabor yang dipilih sebanyak 90 ibu balita yang diperoleh dengan teknik systematic random sampling. Instrumen penelitian menggunakan kuesioner dan data dikumpulkan dengan metoda face to face interview dibantu oleh enumerator yang telah
\end{abstract}


dilatih sebelumnya. Data yang dikumpulkan kemudian dianalisis dengan uji Chi-Square dan Manova Post Hoc Tukey.

Hasil: Ceramah diikuti pemberian booklet dan ceramah diikuti dengan diskusi metoda buzz group sama efektifnya dalam meningkatkan pengetahuan dan sikap ibu dalam pencegahan pneumonia balita. Sedangkan ceramah buzz group lebih efektif meningkatkan praktik ibu dalam pencegahan pneumonia dibandingkan ceramah diikuti pemberian booklet. Hal ini karena dengan metoda buzz grup membuat ibu lebih aktif berpartisipasi dan kreatif dalam memecahkan masalah pencegahan pneumonia dengan melihat pengalaman ibu lainnya.

Kata Kunci: Ceramah, booklet, buzz group, pneumonia, balita

\section{PENDAHULUAN}

Pneumonia balita adalah infeksi akut alveoli paru anak usia 0-5 tahun. ${ }^{(1)}$ Dampak pneumonia bila tidak mendapat pengobatan dengan cepat akan berdampak kematian balita. Pneumonia menyumbang $16 \%$ dari seluruh kematian balita di dunia dan merupakan penyebab kematian nomor tiga di Indonesia pada tahun 2015. (2)(3) Provinsi yang menempati peringkat pertama insiden pneumonia balita tertinggi di Indonesia adalah NTT sebesar 38,5\%. ${ }^{(3)}$ Karakteristik lingkungan dan kondisi masyarakat Sikka, mendukung untuk terjadinya kejadian pneumonia. Faktor risiko diantaranya adalah kasus gizi buruk sebanyak 153 balita $^{(4)}$ tercatat 7,3\% BBLR, proporsi penduduk umur lebih dari 15 tahun yang merokok di dalam rumah sebesar 55,6\%. ${ }^{(5)}$ Suhu panas dengan curah hujan rendah sehingga membuat lingkungan berdebu. Dengan kondisi rumah masih banyak yang berlantai tanah dan ditempati lebih dari satu keluarga secara bersama-sama, serta sebagian warga menggunakan kayu api untuk memasak kebutuhan rumah tangga. ${ }^{(6)}$ Pada tahun
2016 Wilayah Kerja Puskesmas Kopeta menempati peringkat empat tertinggi kasus batuk bukan pneumonia dan pneumonia dari 23 Puskesmas di Kabupaten Sikka. ${ }^{(5)}$

Perilaku sehat ibu yang mendukung pencegahan pneumonia antara lain menutup hidung, mulut ketika batuk, menjauhkan anak dari penderita batuk, segera membawa balita ke fasilitas pelayanan kesehatan bila sakit batuk, mencuci tangan dengan sabun, membuka jendela rumah, membawa balita imunisasi lengkap, menjauhkan anak dari orang yang sedang merokok, memberi ASI eksklusif ketika masih bayi, selalu ada buah dan sayur dalam menu makanan sehari-hari, memakai masker ketika kontak dengan balita sakit, tidak menyimpan barangbarang dalam kamar tidur, memberi vitamin A pada balita usia lebih dari 6 bulan dan tidak membakar sampah disekitar rumah. ${ }^{(7)}$ Pengetahuan ibu berpengaruh terhadap kejadian pneumonia. ${ }^{(8)}$ Semakin baik pengetahuan ibu maka semakin baik pula upaya pencegahan primer penyakit pneumonia 
pada balita. $^{(9)}$ Ibu yang memiliki sikap tidak mendukung terhadap pencegahan pneumonia beresiko 3,37 kali lebih tinggi terkena pneumonia pada balitanya. ${ }^{(10)}$

Peyuluhan metode konseling dan ceramah tentang pneumonia di wilayah kerja Puskesmas Kopeta belum efektif mencapai sasaran. Hal ini disebabkan karena penyuluhan dan konseling yang diberikan diutamakan bagi orang tua yang datang memeriksakan anaknya ke poli Manajemen Terpadu Balita Sakit (MTBS) saja, sementara kesadaran masyarakat untuk membawa anak ke petugas kesehatan masih kurang, Materi penyuluhan belum mencakup pencegahan pneumonia balita dengan lengkap tetapi mengutamakan pencegahan kekambuhan penderita batuk bukan pneumonia dan pneumonia. sehingga pengetahuan ibu dalam pencegahan terjadinya pneumonia masih kurang. ${ }^{(6)(11)}$

Metode ceramah diikuti dengan diskusi buzz group dalam penelitian ini adalah penyuluhan partisipatif pendidikan orang dewasa. Proses belajar dengan metode ini memiliki empat tahap daur belajar yaitu mengalami, menceritakan, mendiskusikan pengalaman, dan menyimpulkan hasil diskusi sebagai pengetahuan baru yang akan mengantarkan peserta mengenai apa yang harus diubah atau dipertahankan dalam pencegahan pneumonia. ${ }^{(12)}$ Penelitian ini bertujuan membandingkan efektivitas ceramah diikuti dengan pemberian booklet dengan ceramah diikuti dengan diskusi buzz group, untuk meningkatkan pengetahuan, sikap dan praktik ibu dalam pencegahan pneumonia balita.

\section{METODE}

Metode penelitian ini adalah quasi experimental design dengan rancangan non-equivalent control group. Penelitian dilakukan di Wilayah Kerja Puskesmas Kopeta, Kabupaten Sikka Nusa Tenggara Timur, dengan waktu penelitian dimulai dari bulan April-Mei 2018. Populasi ibu yang memiliki anak 0-5 tahun, terdaftar di register posyandu Keluahan Nangalimang dan Kabor yang memenuhi kriteria inklusi direkrut sebagai responden. Pemilihan wilayah kelurahan dilakukan secara purposive dengan kelurahan Nangalimang dipilih sebagai kelompok yang diberi perlakuan dan control dengan mempertimbangkan, wilayah tersebut adalah wilayah dengan insiden batuk bukan pneumonia dan pneumonia terbanyak dalam satu bulan terakhir sedangkan ibu balita dipilih dengan kriteria inklusi bependidikan SMP keatas (bias membaca) atau sederajat, kriteria eksklusi yaitu ibu balita atau suaminya yang berprofesi sebagai tenaga medis atau kader kesehatan. Sampel sebanyak 90 responden yang dibagi kedalam tiga kelompok. 
Ceramah booklet 30 responden, ceramah buzz, group 30 responden, dan kelompok kontrol tanpa intervensi 30 responden. Untuk memperoleh jumlah responden bagi masing-masing kelompok dilakukan dengan cara systematic random sampling.

Instrumen yang digunakan dalam penelitian ini adalah kuesioner yang dibuat dengan pernyataan tertutup berdasarkan konsep teori pneumonia balita. Try out kuesioner dilakukan kepada 30 ibu balita di desa Langir Kangae-Sikka. Booklet dikembangkan berdasarkan buku pedoman kader seri kesehatan anak yang diterbitkan Kementrian Kesehatan Republik Indonesia. Pengembangan booklet dengan cara menyadur materi tanpa merubah kalimat aslinya hanya dengan menambahkan arti dari kata bahasa medis diganti dengan bahasa daerah dan menambahkan gambar agar lebih mudah dimengerti. Booklet sudah diujicobakan kepada responden didesa lain yang sama karakteristiknya dan dikonsultasikan kepada Kepala puskesmas Kopeta, dengan mempertimbangkan kata-kata dan gambar yang mudah dimengerti oleh masyarakat setempat. Booklet berisi penjelasan tentang pneumonia meliputi pengertian pneumonia, bahayanya bila terjadi pada balita, penularannya, gejalanya dan pencegahan serta pengobatannya. Variabel demografi meliputi umur, pendidikan, pekerjaan, pendapatan keluarga, jumlah anak dan anak balita, pengalaman sakit, status gizi balita dan pengalaman responden memperoleh informasi tentang pneumonia.

Sebelum intervensi masing-masing kelompok diberikan informed consent dan dilanjutkan dengan pre-test. Kemudian penyuluhan dan pemberian booklet pada kelompok intervensi 1 dan pemberian penyuluhan dan diikuti diskusi buzz group pada kelompok intervensi 2, sedangkan kelompok kontrol hanya diberikan penyuluhan saja. Booklet dapat dibawa pulang untuk dibaca di rumah, sedangkan diskusi tentang pneumonia dalam booklet dilakukan setiap sabtu selama 3 x @60 menit. Pada kelompok penyuluhan diikuti buzz group ceramah berlangsung selama 2 jam dilanjutkan dengan testimony beberapa peserta tentang pengalaman mereka ketika anak mereka sakit pneumonia dan dilanjutkan dengan diskusi selama 2 jam. Buzz group (diskusi oleh 5 kelompok kecil) dilakukan setiap Minggu selama 3 x 60 menit. Diskusi dilakukan setiap minggu tentang pengertian pneumonia, pencegahannya dan deteksi dini. Selanjutnya faktor risiko seperti asap rokok, polusi kendaraan bermotor, polusi asap lainnya yang membuat anak mudah terkena penyakit gangguan pernafasan, Untuk perubahan sikap dan perilaku, setiap kelompok berdiskusi tentang hambatan yang dirasakan dalam pencegahan 
pneumonia balita dan cara pemecahannya berdasarkan studi kasus. Bila balita sakit harus dibawa ke layanan kesehatan bukan pengobatan tradisional dan menjauhkan balita dari asap (asap rokok, anti nyamuk, bakaran sampah, bakaran kayu api) merupakan topik yang didiskusikan oleh kelompok ini. Data penelitian dianalisis dengan uji Chi-Square dan Manova post hoc tukey dengan tingkat kemaknaan 95\% $(\alpha=0,05)$ Penelitian ini sudah mendapat persetujuan etis dari Komisi Etik Penelitian Kesehatan, Fakultas Kesehatan Masyarakat Universitas Diponegoro No. 034/EC/FKM/2018.

\section{HASIL DAN PEMBAHASAN}

Karakteristik responden pada tabel 1 menunjukkan bahwa kebanyakan ibu berumur 19-35 tahun, berpendidikan SMA dan sebagai ibu rumah tangga dengan penghasilan keluarga kebanyakan dibawah UMK. Sebagian besar mempunyai balita satu orang dengan status gizi balita berkategori baik. Kebanyakan ibu belum pernah mendapat penyuluhan tentang pneumonia. Variabel umur, pendidikan, pekerjaan, pendapatan, jumlah balita, status balita dan informasi tentang peneumonia dari ketiga kelompok ibu tidak berbeda secara statistik dengan $\mathrm{p}$ value $>0,05$. Demikian pula pengetahuan, sikap dan praktek ibu dalam pencegahan dan deteksi dini pneumonia pada ketiga kelompok tidak berbeda dengan $\mathrm{p}$ value $>0,05$. Hal ini menunjukkan bahwa karakteristik responden masing-masing kelompok antara kelompok intervensi dan kontrol adalah tidak berbeda atau homogen dan ini merupakan keuntungan dalam desain eskperimen.

$$
\text { Demikian juga variabel }
$$
pengetahuan, sikap dan praktek sebelum intervensi dari masing-masing kelompok intervensi dan kontrol tidak berbeda atau homogen dengan nilai $p$ value berturutturut 0,588; 0,110 dan 0,203 (lihat tabel 2).

Hasil Multivariat Analysis of Varians yang terlihat pada tabel 3 menunjukkan bahwa terdapat peningkatan pengetahuan, sikap dan praktek secara significant setelah intervensi dengan $p$ value 0,000 . Secara statistik terdapat perbedaan bermakna antara sebelum dan sesudah intervensi. Peningkatan pengetahuan kelompok ceramah diikuti pemberian booklet sebesar 5,4 dan ceramah diikuti diskusi buzz group sebesar 4,5. Sedangkan kelompok kontrol hanya terjadi peningkatan sebesar 0,7 poin pada variable pengetahuan. Untuk variabel sikap intervensi ceramah dengan booklet terjadi peningkatan 5,8 dan kelompok ceramah buzz grup 8,9 sedangkan kelompok kontrol hanya 1,1 poin. 
Tabel 1. Distribusi karakteristik responden masing-masing kelompok intervensi dan kontrol

\begin{tabular}{|c|c|c|c|c|}
\hline \multirow{3}{*}{ Karakteritik } & \multicolumn{4}{|c|}{ Kelompok Penelitian } \\
\hline & \multirow[t]{2}{*}{$\begin{array}{c}\text { Ceramah } \\
\text { Booklet }(\mathrm{n}=30)\end{array}$} & $\begin{array}{c}\text { Ceramah } \\
\text { Buzz group }(\mathrm{n}=30)\end{array}$ & $\begin{array}{c}\text { Kontrol } \\
(\mathrm{n}=30)\end{array}$ & \multirow[t]{2}{*}{$p$-value } \\
\hline & & $\mathrm{n} \quad(\%)$ & $\mathrm{n} \quad(\%)$ & \\
\hline \multicolumn{5}{|l|}{ Umur } \\
\hline 19-35 tahun & $22(73)$ & $22(73)$ & $23(76)$ & 0,943 \\
\hline 36-45 tahun & $8(27)$ & $8(27)$ & $7(24)$ & \\
\hline \multicolumn{5}{|l|}{ Pendidikan } \\
\hline SMP & $10(33)$ & $12(40)$ & $9(30)$ & 0,709 \\
\hline SMA & $20(67)$ & $18(60)$ & $21(70)$ & \\
\hline \multicolumn{5}{|l|}{ Pekerjaan } \\
\hline IRT & $23(77)$ & $24(80)$ & $21(70)$ & 0,656 \\
\hline Bekerja & $7(23)$ & $6(20)$ & $9(30)$ & \\
\hline \multicolumn{5}{|l|}{ Pendapatan Keluarga } \\
\hline$<$ UMK & $25(83)$ & $25(83)$ & $23(77)$ & 0,748 \\
\hline$\geq \mathrm{UMK}$ & $5(17)$ & $5(17)$ & $7(23)$ & \\
\hline \multicolumn{5}{|l|}{ Informasi Pneumonia } \\
\hline Pernah & $7(23)$ & $6(20)$ & $7(23)$ & 0,938 \\
\hline Tidak Pernah & $23(77)$ & $24 \quad(80)$ & $23(77)$ & \\
\hline \multicolumn{5}{|l|}{ Jumlah anak balita } \\
\hline Satu & $26(87)$ & $26(87)$ & $23(77)$ & 0,487 \\
\hline$>$ Satu & $4(13)$ & $4(13)$ & $7(23)$ & \\
\hline \multicolumn{5}{|l|}{ Status gizi balita } \\
\hline Kurang & $5(16,7)$ & $4(13.3)$ & $6(20)$ & 0,787 \\
\hline Baik & $25(83,3)$ & $26(86,7)$ & $24(80)$ & \\
\hline
\end{tabular}

Tabel 2. Hasil uji beda pada ketiga kelompok sebelum intervensi

\begin{tabular}{clcc}
\hline No. & \multicolumn{1}{c}{ Variabel } & Nilai $\mathrm{f}$ & $p$-value \\
\hline 1 & Pengetahuan & 0,534 & 0,588 \\
2 & Sikap & 2.265 & 0,110 \\
3 & Praktik & 1.626 & 0,203 \\
\hline
\end{tabular}

Tabel 3. Nilai mean pre-post test hasil uji manova

\begin{tabular}{lcccccccc}
\hline & \multicolumn{2}{c}{$\begin{array}{c}\text { Ceramah } \\
\text { booklet }\end{array}$} & \multicolumn{2}{c}{$\begin{array}{c}\text { Ceramah } \\
\text { buzz }\end{array}$} & \multicolumn{2}{c}{ Kontroup } & & \multirow{2}{c}{$\begin{array}{c}p \text { - } \\
\text { Value }\end{array}$} \\
\cline { 2 - 7 } & pretest & posttest & pretest & posttest & pretest & posttest & & \\
\hline Pengetahuan & 11,6 & 17,7 & 11,7 & 16,9 & 12.0 & 12,7 & 214,7 & 0,000 \\
Sikap & 14,4 & 20,2 & 13,6 & 22,5 & 14,6 & 15,7 & 245,3 & 0,000 \\
Praktik & 12,27 & 20,0 & 12,7 & 24,6 & 13,0 & 13,2 & 555,6 & 0,000
\end{tabular}


Tabel 4. Hasil uji post hoc tukey

\begin{tabular}{|c|c|c|c|c|}
\hline \multirow{3}{*}{ Variabel } & \multicolumn{3}{|c|}{ Hasil Pengukuran } & \multirow[b]{3}{*}{ Nilai $p$} \\
\hline & \multirow{2}{*}{$\begin{array}{l}\text { Rata-rata } \\
\text { Perbedaan }\end{array}$} & \multicolumn{2}{|c|}{$95 \% \mathrm{CI}$} & \\
\hline & & Lower & Upper & \\
\hline $\begin{array}{l}\text { Pengetahuan } \\
\text { Ceramah booklet } \\
\text { Ceramah buzz group }\end{array}$ & 0,33 & $-0,46$ & 1,13 & 0,583 \\
\hline $\begin{array}{l}\text { Ceramah booklet } \\
\text { Kontrol }\end{array}$ & 2,25 & 1,46 & 3,04 & 0,001 \\
\hline $\begin{array}{l}\text { Ceramah buzz group } \\
\text { Kontrol }\end{array}$ & 1,92 & 1,12 & 2,71 & 0,001 \\
\hline $\begin{array}{l}\text { Sikap } \\
\text { Ceramah booklet } \\
\text { Ceramah buzz group }\end{array}$ & $-0,77$ & $-1,74$ & 0,20 & 0,152 \\
\hline $\begin{array}{l}\text { Ceramah booklet } \\
\text { Kontrol }\end{array}$ & 2,12 & 1,15 & 3,09 & 0,001 \\
\hline $\begin{array}{l}\text { Ceramah buzz group } \\
\text { Kontrol }\end{array}$ & 2,88 & 1,92 & 3,85 & 0,001 \\
\hline $\begin{array}{l}\text { Praktik } \\
\text { Ceramah booklet } \\
\text { Ceramah buzz group }\end{array}$ & $-2,53$ & $-3,35$ & $-1,72$ & 0,001 \\
\hline $\begin{array}{l}\text { Ceramah booklet } \\
\text { Kontrol }\end{array}$ & 3,03 & 2,22 & 3,85 & 0,001 \\
\hline $\begin{array}{l}\text { Ceramah buzz group } \\
\text { Kontrol }\end{array}$ & 5,57 & 4,75 & 6,38 & 0,001 \\
\hline
\end{tabular}

Sedangkan variabel praktek kelompok ceramah booklet meningkat sebesar 7,73 dan kelompok ceramah buzz. grup meningkat 11,9 sedangkan kelompok kontrol hanya meningkat sebesar 0,2. Perbedaan peningkatan pengetahuan, sikap dan praktek responden setelah pemberian intervensi pada masing-masing kelompok intervensi terjadi karena adanya intervensi yang berbeda. Pada intervensi dengan menggunakan diskusi buzz grup terlihat lebih tinggi dibandingkan dengan booklet. Hal ini karena menggunakan diskusi masalah riil/ nyata yang dihadapi oleh ibu sehari-hari dalam menghadapi penyakit pneumonia balitanya dan membahas solusi dari masalah yang dihadapi tersebut dengan role playing serta adanya contoh melalui testimony dari pengalaman peserta menambah kesadaran dan keyakinan responden. Pemberian informasi kesehatan dengan metoda buzz grup dan 
booklet adalah suatu proses belajar, seseorang dapat dikatakan belajar apabila didalam dirinya terjadi perubahan dari tidak tahu menjadi tahu dari tidak faham menjadi faham. ${ }^{(13)}$ Responden perlakuan juga belajar tentang pneumonia balita sehingga terbentuk kesadaran dan keyakinan untuk membentuk sikap yang pada akhirnya terjadinya perubahan perilaku.

Beberapa komponen secara bersama-sama dapat membentuk sikap seseorang secara utuh melalui proses pengetahuan, kesadaran, pikiran, keyakinan dan emosi. ${ }^{(14)}$ Responden perlakuan telah memiliki pengetahuan tentang pneumonia, pengetahuan ini membawa responden untuk berpikir agar balitanya tidak sakit pneumonia. Proses berpikir ini tentunya melibatkan aspek emosi dan keyakinan membuat responden memiliki sikap mendukung terhadap pencegahan pneumonia ${ }^{(14)}$ dan selanjutnya mempraktikkan pencegahan pneumonia tersebut.

Hasil penelitian ini sesuai dengan teori Lawrence Green yang menggambarkan kerangka Predisposing, Reinforcing, Enabling factors mempengaruhi perilaku seseorang. Melalui intervensi pendidikan kesehatan, maka faktor penyebab perilaku tersebut dapat ditingkatkan. ${ }^{(14)}$ Penelitian ini juga sejalan dengan hasil penelitian sebelumnya yang menyimpulkan bahwa ada pengaruh pemberian ceramah booklet terhadap peningkatan pengetahuan, sikap dan praktik seseorang. ${ }^{(15)(16)(17)}$ Penelitian ini tidak sejalan dengan Vahedian yang membuktikan bahwa booklet tidak efektif dalam meningkatkan praktik siswa tentang gizi, hal ini dikarenakan dalam pembelajaran melalui booklet, siswa tidak langsung bertemu dengan pemberi informasi, sehingga tidak ada partisipasi aktif yang dapat meningkatkan motivasi siswa untuk mengikuti pedoman yang diberikan oleh booklet dibandingkan seperti dalam pembelajaran ceramah secara langsung yang terjadi interaksi langsung antara pembicara dan audiences. ${ }^{(18)}$

Berdasarkan uji post hoc tukey pada tabel 4 membuktikan ceramah booklet dan ceramah buzz group sama efektifnya, dalam meningkatkan pengetahuan, sikap dan praktik responden tentang pneumonia dibandingkan kelompok control dengan nilai $p$ value masing-masing 0,001 . Responden dengan diberikan ceramah booklet dan ceramah buzz group samasama menggunakan indera untuk penyerapan materi penyuluhan, dan terdapat tiga faktor yang mempengaruhi perubahan sikap yaitu sumber yang terpercaya, isi pesan, kebutuhan penerima pesan. Penelitian ini sejalan dengan temuan penelitian sebelumnya yang menyimpulkan penyuluhan ceramah 
booklet dan diskusi sama efektifnya dalam meningkatkan sikap. ${ }^{(19)}$ Hasil penelitian ini berbeda dengan hasil temuan Soleimanekhtiary menjelaskan diskusi lebih efektif dalam meningkatkan sikap siswa tentang obesitas dibandingkan penyuluhan dengan booklet. Hal ini dikarenakan diskusi, dapat merangsang siswa lebih aktif dan kreatif dalam memberikan gagasan pemecahan masalah, sehingga membimbing siswa bersikap atau membuat keputusan. ${ }^{(20)}$

Penyuluhan ceramah buzz group lebih efektif untuk meningkatkan praktik responden dalam pencegahan pneumonia balita, selisih rata-rata perbedaan sebesar 2,53 ( $p$ value 0,000) Perbedaan praktik antara kelompok ceramah booklet dan buzz group disebabkan proses belajar yang berbeda. Penyuluhan dan tanya jawab terkait materi pneumonia balita dalam booklet berlangsung vertikal, bersifat menggurui sehingga peningkatan praktik responden menjadi lebih kecil. Penyuluhan ceramah buzz group merupakan pendidikan orang dewasa yang berlangsung horizontal. Peserta diajak berdiskusi dan merasakan apa yang dialami oleh orang lain yang akhirnya dijadikan pelajaran bila peserta mengalami hal yang sama. Peserta mengungkapkan dan diskusi pengalaman tentang hambatan yang pernah peserta lain alami dalam melakukan pencegahan pneumonia. Penyuluhan ini mengarahkan peserta pada pemahaman mengenai sesuatu yang harus diubah, dan dipertahankan. Responden percaya bahwa manfaat perilaku yang disampaikan oleh penyuluh dapat mengurangi risiko balita mereka dari kejadian pneumonia. Penelitian ini mendukung temuan penelitian sebelumnya yang menyimpulkan bahwa diskusi kelompok lebih efektif dibandingkan booklet dalam meningkatkan praktik seseorang. ${ }^{(19)}$

\section{SIMPULAN}

Karakteristik ibu balita seperti umur, pendidikan, pekerjaan, pendapatan keluarga, informasi pneumonia, jumlah dan status gizi balita dari ke-tiga kelompok sebelum intervensi adalah tidak berbeda yang berarti kondisi kelompok perlakuan dan kontrol sebelum intervensi adalah homogen sehingga menguntungkan untuk penelitian ini. Demikian juga tingkat pengetahuan, sikap dan praktik ibu balita dalam pencegahan pneumonia dan deteksi dini dari kelompok perlakuan dan kontrol sebelum intervensi adalah sama. Kelompok dengan intervensi ceramah booklet dan ceramah buzz group memperlihatkan hasil yang sama efektifnya dalam meningkatkan pengetahuan dan sikap ibu tetapi kelompok dengan intervensi ceramah diikuti buzz. group lebih efektif meningkatkan praktik ibu dalam pencegahan pneumonia dibanding ceramah diikuti pemberian 
booklet. Saran bagi Puskesmas Kopeta, pelaksanaan penyuluhan tentang pneumonia balita lebih baik menggunakan ceramah diikuti diskusi buzz group sebagai salah satu metode yang membuat ibu balita menjadi aktif dan kreatif memecahkan masalah dalam mencegah pneumonia pada balitanya.

\section{UCAPAN TERIMA KASIH}

Ucapan terima kasih kami tujukan kepada para ibu yang telah bersedia berpartisipasi menjadi responden dalam penelitian ini serta para bidan dari puskesmas Kopeta yang membantu peneliti dalam melaksanakan penelitian ini. Ucapan terima kasih juga kepada Rektor Universitas Nusa Nipa dan Ketua Yayasan Pendidikan Tinggi Nusa Nipa Maumere yang telah memberikan peneliti izin dan kesempatan mengikuti program magister di UNDIP serta teman-teman kuliah seperjuangan yang telah memberikan motivasi dalam menyelesaikan penelitian ini.

\section{KEPUSTAKAAN}

1. Ditjen P2P. Modul Tatalaksana Standar Pneumonia. Jakarta: Kementerian Kesehatan RI; 2012. 2 p.

2. WHO. Pneumonia [Internet]. 2016. Available from: http://www.who.int/mediacentre/facts heets/fs331/en/.
3. Kemenkes RI. Laporan Hasil Riset Kesehatan Dasar (Riskesdas) Indonesia. Jakarta: Badan Penelitian dan Pengembangan Kesehatan; 2013.

4. Dinas Kesehatan Provinsi NTT. Profil Kesehatan Provinsi Nusa Tenggara Timur [Internet]. Kupang; 2015. Available from: www.depkes.go.id/resources/downloa d/profil/PROFIL_KES.../19_NTT_201 5.pdf

5. Dinkes Kab Sikka. Profil Dinas Kesehatan Kabupaten Sikka. Maumere; 2016.

6. Liadewi VN, Agustina SA. Kejadian Pneumonia Balita di Maumere Flores NTT. Media Ilmu Kesehat. 2016;5(2):99-106.

7. Sundari S, Pratiwi, Khairudin. Perilaku Tidak Sehat Ibu yang Menjadi Faktor Resiko Terjadinya ISPA Pneumonia pada Balita. J Pendidik Sains. 2014;2(3):141-7.

8. Azizah M, Qoriaty NI, Fahrurazi. Tingkat Pengetahuan dan Pendidikan Ibu balita dengan Kejadian Penyakit Pneumonia Pada Balita Di Kelurahan Keraton Kecamatan Martapura. J AnNadaa. 2014;1(1):1-4.

9. Supran, Ningtyas R, Ajiningtyas ES. Hubungan Pengetahuan Ibu dengan upaya Pencegahan Primer Penyakit ISPA pada Balita. J Borneo Cendekia. 2017;1(1):45-52. 
10. Sutangi H. Hubungan Pengetahuan dan Sikap Ibu dengan Kejadian Pneumonia Balita di desa Telukagung Wilayah Kerja Puskesmas Plumbon Kecamatan Indramayu. J Unwir AFIASI. 2015;1(1):1-7.

11. Asti FN. Gambaran Pengetahuan Ibu Balita Tentang Penyakit ISPA di Wilayah Kerja Puskesmas Kopeta Kabupaten Sikka. [KTI]. Maumere: Universitas Nusa Nipa; 2016

12. Ditjen Bina Kesehatan Masyarakat. Pedoman Pelaksanaan Kelas Ibu Balita. Jakarta: Departemen Kesehatan RI; 2009. 11-14 p.

13. Waryana. Promosi Kesehatan Penyuluhan dan Pemberdayaan Masyarakat. Yogyakarta: Nuha Medika; 2016.

14. Notoatmodjo S. Promosi Kesehatan dan Perilaku Kesehatan. Jakarta: Rineka Cipta; 2012.

15. Aini RN, Arief YS, Aliz NK. Buzz group dalam Meningkatkan Perilaku Pemberian Makanan Pendamping ASI. Pediomaternal Nurs J. 2014;3(1):13644.

16. Varghese NM, Kumari V, Madanlal M. Evaluation of Effectiveness of an Informational Booklet on Prevention of Osteoporosis in Terms of
Knowledge Attitude an Expressed Practices of Working Women. J Nurs Heal Sci. 2013;2(5):10-8.

17. Jena M. Effectiveness of Information Booklet on Knowledge \& Practice about Prevention of Pneumonia among Mothers of Under Five Children. IOSR-Journal Nurs Heal Sci. 2014;3(1):25-30.

18. Vahedian M, Sadeghi R, Farhadlu R, Nazeri A, Dehghan A, Barati H. Effect of Educational Booklet and Lecture on Nutritional Behavior Knowledge and Attitude on Third-Grade Male Guidance School Students. J Community Heal Res. 2014;3(1):1-12. 19. Hajbaghery MA, Faraji M. Comparison of effect between group discussion and educational booklet on Iranian nursing students' attitude and practice toward patient privacy. J Educ Eval Health Prof. 2016;13(29):1-10.

20. Soleimanekhtiary Y, Shojaeezadeh D, Zeraati H., 2008. Comparison between the effect of two methods of health education (booklet and group discussion) for prevention behaviors of obesity in primary school students in Tehran. Megazine of Yazd Med-Sci University 13(6),pp.1-10. 